\title{
Behavioural Economics Approach: Using Investors Sentiment Indicator for Financial Markets Forecasting
}

\author{
Marius LIUTVINAVIČIUS ${ }^{1}$, Jelena ZUBOVA ${ }^{2}$, \\ Virgilijus SAKALAUSKAS ${ }^{1}$ \\ ${ }^{1}$ Vilnius University, Kaunas Faculty \\ ${ }^{2}$ Vilnius University, Institute of Mathematics and Informatics \\ marius.liutvinaviciuseknf.vu.lt, jelena.zubova@mii.vu.lt, \\ virgilijus.sakalauskaseknf.vu.lt
}

\begin{abstract}
This research focus on prediction of anomalous situations in financial markets. It investigates if the indicator of investors' sentiment can be used to eliminate the factor of irrational behaviour and increase the profits. The overview of existing models for financial crisis forecasting is presented in this paper. Financial and sentiment-based indicators are overviewed and the general classification of both kind of indicators is suggested. The methodology of using investors' sentiment indicator together with different strategies are presented. The simulation of investment to different financial instruments was used in order to test the proposed method. The results show that sentiment based indicator can successfully prevent the investments from losses.
\end{abstract}

Keywords: Behavioural economics, financial markets, asset price forecasting

\section{Introduction}

General instability of financial markets and recent financial crises led to intensive search for new ideas and methods in asset pricing and risk management. Recent research works confirm the idea of irrationality of financial markets versus their efficiency. The 2013 Nobel Memorial Prize in Economic Sciences was jointly received by Robert Shiller, Eugene Fama and Lars Peter Hansen for their empirical analysis of asset prices (Fama, 1970; Campbell et al., 2014). Robert Shiller strongly emphasized the irrationality of financial markets (Shiller et al., 2014). They are influenced not only by economic, social or geopolitical factors. Expectations and fears of investors, manipulation of information in media streams and social networks play very important role as well. Huge amount of information emanating from sources of various origin create the factors that should be incorporated in financial markets forecasting. This is growing the demand for applications of analytical methods capable to process information streams characterized as big data.

Our research object is the anomalous situations in financial markets and factors determining them. We perceive financial markets as dynamic systems of interacting agents which modelling and prediction are based on computer technology. The problem of increasing the effectiveness of identification of anomalous situations in financial 
markets is solved in this article. The models of real investment processes are designed and simulated in order to experimentally analyse various possible scenarios. The research goal is to offer new methods for identification of anomalous situations. These methods should improve the investment performance and reduce risk level.

In our assumption, financial stability relies not only on good economic and financial fundamentals, but irrational behaviour of investors (as part of the system) must be evaluated too. Every single investor differs by his experience, financial literacy, goals and risk tolerance. And all of them are affected by their fears, expectations, impact of media news or social networks streams.

In the second section we present the literature overview of existing methods for financial crisis - the most obvious anomalous situation - prediction. The third section is indented to overview both the financial and investors sentiment indicators. The fourth section describes the methodology of our research. It uses the indicator of investors' mood to predict the changes of asset prices. Finally, the last section presents the results of three case studies. We simulated the investment process to three exchange traded funds (ETF): SPDR S\&P 500, SPDR Euro STOXX and SPDR Gold Shares.

\section{Overview of existing models for financial crisis forecasting}

Financial crises can be treated as the most obvious and biggest consequences having case of abnormal situation in financial markets. In this section, we present the brief summary of the surveys about existing financial crisis prediction models recently made by different authors.

Financial crises are usually described as failures of financial institutions or sharp falls in asset prices (Tularam and Subramanian, 2013). G. Tularam and B. Subramanian argue that it is useful to classify crises in four groups: currency crises; sudden stop (or capital account or balance of payments) crises; debt crises; and banking crises. According to Rajeshwar (2010), in the 19th and early 20th centuries many financial crises were associated with banking panics, and many recessions coincided with these panics, but other situations that are often called financial crises include stock market crashes and the bursting of financial bubbles, currency crises and sovereign defaults.

Claessens and Kose (2013) state that while it is easy to design quantitative methods to identify currency (and inflation) crises and sudden stops, the identification of debt and banking crises is typically based on qualitative and judgmental analyses. Another issue is that different types of crises are likely to overlap (Claessens and Kose, 2013).

Accoriding to Bucevska (2011), Rajeshwar (2010) and Mariano et. al. (2002), the historical development of financial crisis prediction models can be grouped into three generations. In some latest works (e.g. Tularam and Subramanian (2013)) we can find financial crisis models categorized into four generations. Each model reflects the distinct mechanism that is espoused as the major cause of such crises (Mariano et. al. 2002). However, Krznar (2004) claimed that these models do not offer consensus on the causes of financial crises since they identify different determinants of a crisis. This causes the demand for further researches in financial crisis prediction area. The following parts of this section present the insights and findings made by these authors about financial crisis prediction models. 


\subsection{First-generation models}

First-generation models of currency crises were based on macroeconomic fundamentals and speculations. They focused on long run, unique equilibrium, fiscal deficits and monetary policies. The models explained currency crises by poor domestic macroeconomic conditions. Also, they emphasized the relationship between speculation attack in foreign exchange market and macroeconomic variables (Tularam and Subramanian, 2013).

Initiated by the Latin American debt crisis at the beginning of 1980s and pioneered by Krugman (1979), the first generation of theoretical models of crisis focused on the role of the weak economic and financial fundamentals as potential early warning indicators of currency crisis. They included such indicators as the gradual decline in international reserves, growing budget and current account deficits, domestic credit growth and gradual exchange rate overvaluation (Bucevska, 2011). These models tended to focus on the role of such fundamentals as the unsustainable fiscal policies in the face of the fixed exchange rate as the major cause of an eventual currency crisis (Mariano et al., 2002). According to the first-generation models, weak economic fundamentals are more vulnerable to speculative attacks (Singh, 2010).

\subsection{Second-generation models}

The second generation of models was developed by adding features of self-fulfilling expectations to currency crises. The main innovation of these models lies in identifying the role that the "expectations" of the economic agents (investors) may play in precipitating currency crises (Bucevska, 2011).

The development of these currency crises prediction models were motivated by the EMS currency crisis in 1992-93, where some countries, such as the UK and Spain, suffered crises despite having adequate international reserves, manageable domestic credit growth and non-monetized fiscal deficits (Mariano et al., 2002).

Second-generation models of currency and banking crises introduced speculation based self-fulfilling expectations that need not be tied to fundamentals. The models focused on short run, multiple equilibriums, government policies and speculations expectations. Second generation models explained the relationship between economic fundamentals and a speculative attack period. These models viewed currency crisis not as a result of bad policy, but as a shift in expectations. Second-generation models showed how a spontaneous speculative attack on a currency can cause a crisis, even if fiscal and monetary policies are consistent (Tularam and Subramanian, 2013).

These models do not reject the role of weak fundamentals, but suggests that selffulfilling expectations appear to be the main cause of crises (Singh, 2010).

\subsection{Third-generation models}

After the Asian and the Latin American crisis during the middle 1990s, when the economic fundamentals of the affected countries were found to be rather sound before the outbreak of the crisis, it was found that problems in the financial sector trigger the financial crises. Therefore, the third generation of theoretical models additionally included the financial sector indicators derived from aggregate balance sheets of banks (Bucevska, 2011). 
Third-generation models made a connection between banking and international currency markets. The models explained the relationship between financial fragility and currency crisis. In these models the macroeconomic fundamentals were strong in the context of high annual growth rates, a low inflation rate and budget deficits, strong capital inflows and manageable current account deficits (Tularam and Subramanian, 2013).

The third generation models combined the weaknesses in the economic fundamentals of early generation models with weaknesses in the banking sectors. For this reason, the third generation models are also known as twin crises models (Singh, 2010).

These models were based on the notion of 'contagion' where the mere occurrence of a crisis in one country increases the likelihood of a similar crisis elsewhere (Mariano et al., 2002).

The joint occurrence of banking, currency and debt crises associated with the global financial crisis of 2008 motivated the interest in studying the determinants of the "crisis of the triad": banking, debt and currency crisis (Bucevska, 2011).

\subsection{Fourth-Generation Models}

Tularam and Subramanian (2013) distinguished 4 generations of crisis prediction models. According to them, the causes of financial crises are multiple, but the models of financial crises revolve around four generational models.

According to them, Krugman (2001) proposed a fourth-generation crisis model, which may not be a currency crisis model, but a more general crisis model in which asset prices other than the exchange rate play the major role. They also highlighted Breuer (2004), who emphasized economic and financial rules and regulations, shareholder rights, transparency and supervision over the financial system, government distortions, political and sociological variables (Tularam and Subramanian, 2013).

Recent early warning models typically use a wide array of quantitative leading indicators of vulnerabilities. Indicators capture vulnerabilities that stem from or are centred in the external, public, financial, nonfinancial corporate or household sectors and combine these with qualitative inputs (Claessens and Kose, 2013).

Another important statement of Tularam and Subramanian (2013) is that agent-based simulations can handle a far wider range of nonlinear behaviour than conventional equilibrium models. The financial markets are complex systems that involve human activities and behaviour. Agent based modelling appears to be one of the best ways to explain the behaviour of the economic systems, since it does not assume that the economy can achieve a settled equilibrium (Tularam and Subramanian, 2013).

\subsection{Two approaches for developing models of early warning systems}

There are essentially two main approaches which have been used for developing the early warning models: the econometric approach and the "signals" approach (Bucevska, 2011).

The econometric approach estimates limited dependent variable probability models (a probit or a logit model) for prediction of the outbreak of a financial crisis. These models estimate a probability relationship with a discrete dependent variable. They can tell which of the explanatory variables included in the model has a predictive power and can also show the probability of a future crisis (Bucevska, 2011). Such approach was 
illustrated by Eichengreen and Rose (1998) for currency crisis and Demirguc-Kunt and Detragrache (1998) for prediction of banking crises (Mariano et al., 2002).

Instead of summarizing the probability of crisis in one number between zero and one, the "signals" approach uses a non-parametric method to ascertain the risk of financial crisis: a variable is considered to be issuing a warning signal if it goes beyond a certain "threshold" level in the bad direction (Bucevska, 2011). This methodology was adopted by Kaminsky and Reinhart (1996), and Kaminsky, Lizondo and Reinhart (1998) (Mariano et al., 2002).

\section{Combining financial and irrational indicators to forecast anomaly situations in financial markets}

\subsection{Financial indicators and methods used for anomaly detection}

When constructing the model of early warning system there is a need to select the explanatory variables - the indicators of a financial crisis. Kaminsky et al. (1998) reviewed a large variety of indicators and grouped them into six categories: a) The external sector (capital account, external debt profile, current account international variables); b) The financial sector (financial liberalization and other financial variables); c) The real sector (real GDP growth, the output gap, employment/unemployment, wages, changes in stock prices); d) The public finances (fiscal variables); e) Institutional and structural variables; f) Political variables (Tularam and Subramanian, 2013).

Mariano (2002) suggested such the potential early warning indicators of speculative attacks: the gradual decline in international reserves, growing budget and current account deficits, domestic credit growth, and gradual exchange rate overvaluation.

Bucevska (2011) included a relatively wide array of potential early warning indicators and classified them into groups: a) Fiscal variables (government budget balance as a percentage of GDP); b) Financial sector variables (ratio of domestic bank loans to GDP, decline in total bank deposits to GDP); c) External sector (current account) variables (trade deficit as a percentage of GDP, current account deficit as a percentage of GDP, growth rate of exports, real effective exchange rate as a deviation from HP trend); d) External sector (capital account) variables (real interest rate differential as a difference between domestic and foreign short-term interest rate, capital flight, ratio of gross external debt to export); e) Domestic real sector variables (real GDP growth rate).

Tularam and Subramanian (2013) argue that any set of indicators together may not provide an over-all picture, but interactions among indicators should be pursued. According to them, common sense and guesswork is used, but is not sufficient for representing real behaviour.

Since international financial markets can play multiple roles in transmitting and causing various types of crises, banking system measures, such as exposures to international funding risks and the ratio of non-core to core liabilities, have been found to help signal vulnerabilities (Claessens and Kose, 2013).

Shen and Jia (2014) studied financial crisis of listed companies in China Manufacture Industry. Firstly, the method of principle component analysis was used to abstract useful information from the training data. Secondly a prediction model of financial crisis was constructed with the method of Support Vector Machine. 
Mariano (2002) argued for Markov Switching Modelling as a methodological approach to the issue of predicting financial and economic crises. Liu and Lindholm (2006) used a fuzzy (c-means based fuzzy chestering) method to find important economic indicators for the prediction of crisis at the time of crisis as well as pre and post crisis (Tularam and Subramanian, 2013).

\subsection{Investors sentiment indicators for financial markets forecasting}

Behavioural economics tells us that emotions can affect individual behaviour and decision making. When trying to capture the patterns of investors' behaviour social media and web news can be very useful. The latest researches show the advantages of the methods that use investors' sentiments to predict the stock markets (Shahzad et al., 2017; Oliveira et al., 2016; Song et al., 2017; Renault, 2017; Guo et al., 2017; Chau et al., 2016). Most of works focus on short term (e.g. next day) prediction of specific stocks. Our goal is to adapt such methods for risk level identification and prediction of financial crisis or bigger price falls. The possibility to identify anomalous collective behaviour of investors can also help to prevent market bubbles.

According to Ranco et. al. (2015), there are three major classes of data: web news, search engine queries and social media (Ranco et al., 2016). Summing up we can state that one group of researches focus on the volume of messages or queries and another group explores the contents of them. Recent researches suggest that the news may be unpredictable, but very early indicators can be extracted from online social media to predict changes in various economic and commercial indicators (Bollen et al., 2010).

Houlihan and Creame (2014) investigated if sentiments extracted from social media and options market are correlated with future asset prices. They used both social media sentiment and investors' sentiment captured through the call-put ratio with several predictive models to forecast market price direction. Authors concluded that injection of news into the marketplace in conjunction with various trader behaviour of the options market help explain both the volatility and evolution of assets price.

Ranco et. al. (2015) investigated the relations between Twitter and financial markets. They found a significant dependence between the Twitter sentiment and abnormal returns during the peaks of Twitter volume. They also showed that sentiment polarity of Twitter peaks implies the direction of cumulative abnormal returns. Bollen et al. (2010) extracted the mood state of a large number of users on a stock blogging site and used it to predict moves of the Dow Jones Industrial Average index.

Gruhl et al. (2005) showed that blogs can predict "real-world" behaviour. Studying data might result in the detection of a statistical relationship between a social mediabased measure (e.g., the number of likes on Facebook) and the outcome of interest (Schoen et al,, 2013). Ranco et. al. (2015) also reviewed various attempts to use social networks and found such approaches: the stock price reaction to news, the role of macroeconomic news in stock returns, the role of news in trading actions, the relation between the sentiment of news and return predictability. Another way to extract investors' sentiment is analysing search engine queries, e.g. Google trends. Interesting works in this area were made by Bordino (2012) and Kristoufek (2013).

However, the extraction of investors' sentiment is not as easy as it might seem. As Schoen (2013) emphasized, most of the models make assumptions that users are expressing their actual opinions instead of trying to "cheat" the market. This is why interpreting the opinion expressed in social media contents is difficult: some users are 
trying to "cheat" by either spreading misinformation or by producing an abnormally high volume of conversation by means of automated accounts (Schoen et al,, 2013).

We can conclude that financial social media data do have a statistically significant impact on stock returns and such type indicators should be included in market prediction models.

\subsection{The extended classification of different kind indicators}

In this section we suggest the classification of indicators most commonly used by researchers and financial experts to predict the stock market. The main contribution of us compared to previous works is the addition of irrational factors to the traditional sets of indicators (Fig. 1). The set of indicators can be further extended, but it shows the indicators usually used by authors of this paper.

Traditionally fundamental and technical analysis are used for market risk evaluation and asset pricing. As fundamental analysis can be divided into a) economic, b) industry and c) company categories, we separated the economic analysis factors from financial markets indicators that can be used for analysis of single companies and entire industries.

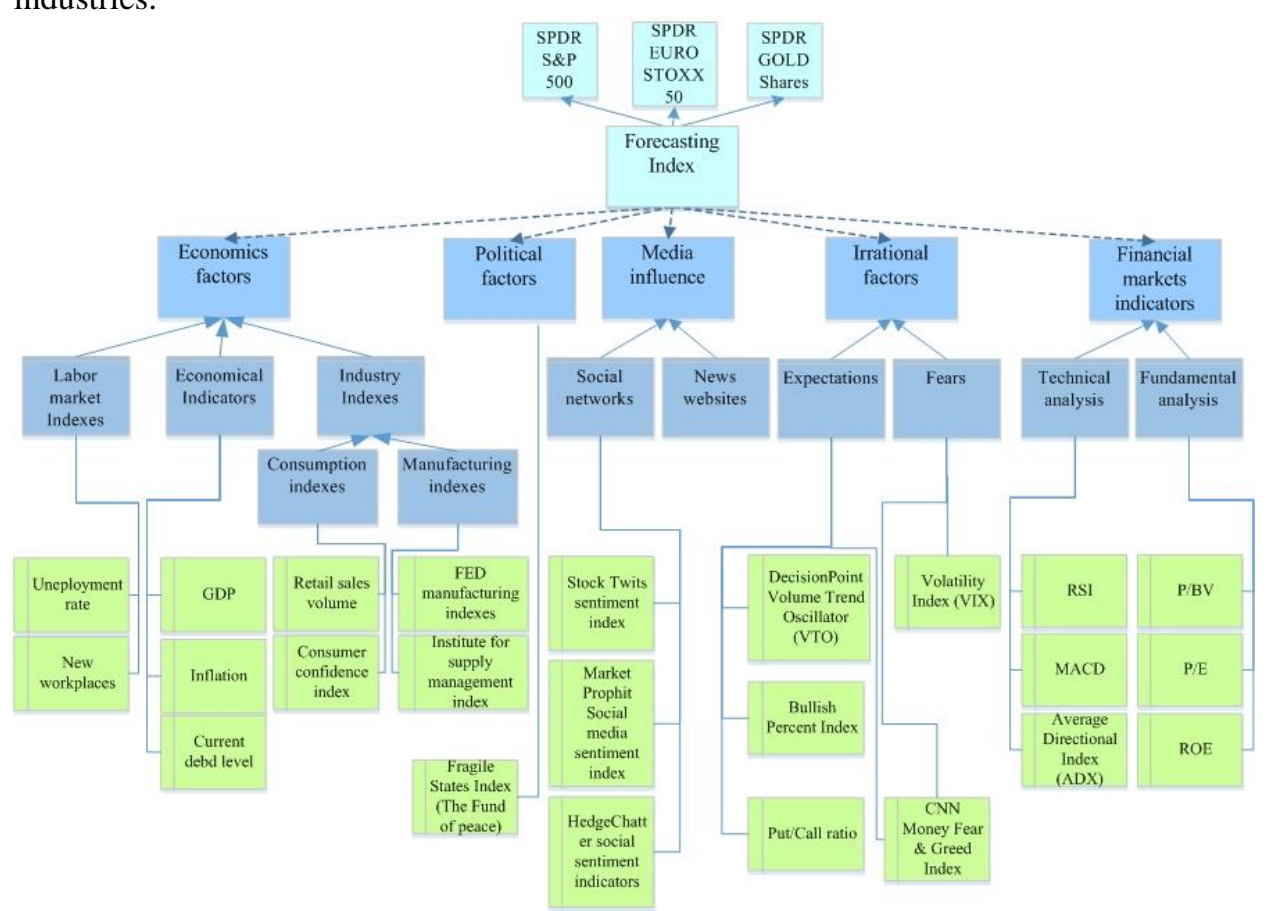

Fig. 1. Indicators for decision support systems

In the Economic factors category there are such indicators as Inflation rate or GDP growth rate. We distinguished Labour market indexes (e.g. Unemployment rate, New workplaces rate), Manufacturing indexes (e.g. FED Manufacturing index, Institute for supply management index) and Consumption indexes (e.g. Retail sales volume, Consumer confidence index). Political impact factors (e.g. Fragile stability index) can be separated too. 
When analysing the financial markets both fundamental analysis indicators $(P / E$. $P / B V, R O E$ etc.) and technical analysis indicators (RSI, MACD etc.) are used. However, in our approach we focus on irrational factors affecting investors' decisions. We distinguished some technical analysis indicators that represent the level of market fears (e.g. Volatility index) or expectations (e.g. Put/Call ratio, Bullish percent index, Decision Point Volume Trend Oscillator).

New technologies already allow analysing big data generated by social networks or media streams. This extends the scope of analysed factors and allows creating new ones. Such example is CNN Money Fear and Greed Index (WEB, a). There are also successful attempts to create quantitative indicators of investors' expectations by analysing their social networks activities, e.g. StockTwits sentiment index (WEB, b), Market Prophit social media sentiment index (WEB, c), HedgeChatter social media indicators (WEB, d). Our aim is to incorporate such information into prediction of anomalous situations in financial markets.

\section{Research methodology}

\subsection{Previous findings}

During our previous research of the factors, affecting investment funds efficiency (Liutvinavicius and Sakalauskas, 2011), the investment strategies were investigated in order to maximize returns and reduce the risk. The special tool was created and used to simulate the accumulation depending on the rate of return, the accumulation period, the level of contributions, the profitability of fund and other factors. It showed that a volatile return rate should be used to accurately simulate the accumulation of high-risk investments. In the next step the dynamics of fund portfolio were investigated by using adaptive simulation models (Liutvinavicius and Sakalauskas, 2012). The proposed model introduced adaptive variables used in the portfolio simulation. Volatile values of return rate, contributions and fees were used in calculations. An important advantage of the described simulator was the ability to see not only the final portfolio value, but also the overall process of its development. This provided a better understanding of the accumulation process itself. The investigation of different investment strategies revealed that the biggest losses during the peak of the crises are caused by emotion-based decisions and lack for financial literacy. The common behaviour of unprofessional investors leads to losses up to 50\% (Liutvinavicius and Sakalauskas, 2012). Our goal is to find the ways to eliminate this gap caused by irrational factors.

\subsection{Methodology for using the indicator of investors' sentiment}

In this research we use investors' sentiment indicator to eliminate the factor of irrational behaviour and increase the effectiveness of investment. Too much fear can sink stocks well below where they should be and too much greed can bid up stock prices way too far (WEB, a). Commonly the indicators of investors' sentiment are used as signal to predict the stock price for the next day. We want to adapt such indicator for long-term periodical investment and cases when decisions are made weekly or monthly. For our research we chose CNN Money Fear and Greed Index (WEB, a), which represents the current level of investors' sentiment. We calculated the sentiment index 
values using similar methodology as CNN Money do. There are 7 indicators used, each having equal power:

- Market Volatility: the VIX index, which measures volatility;

- $\quad$ Stock Price Momentum: the S\&P 500 value versus its 125-day moving average;

- $\quad$ Stock Price Strength: the number of stocks hitting 52-week highs compared to that hitting lows on the New York Stock Exchange;

- Put and Call Options: the put/call ratio, which compares the trading volume of bullish call options relative to the trading volume of bearish put options;

- $\quad$ Stock Price Breadth: the volume of shares trading in stocks on the rise versus those declining;

- $\quad$ Safe Haven Demand: the difference in returns for stocks versus treasuries;

- Junk Bond Demand: the spread between yields on investment grade bonds and junk bonds.

Fig. 2 presents the values of investors' sentiment indicator in comparison to SPDR S\&P 500 ETF values. When the value of indicator is above ' 50 ' it means investors are greedy. When it is below ' 50 ' it means there are more fears in the market. This indicator was chosen because of its wide variety of components. In the future researches we will try to add Social media sentiment factor to this indicator.

\subsection{Simulation of investment to ETF}

This section presents a methodology that we used for simulation of the real process of investment to exchange traded funds (ETF). The model contains variables that affect each other in time. The tool simulates the changes of portfolio value depending on funds' unit price. Unit prices correspond to real historical data of selected ETF. All decisions to buy or sell assets are made accordingly to fear and greed indicator values.

First of all, the amount of contribution is calculated in accordance to indicator. When indicator value is extremely low - below Lower contribution threshold (LCT) - we can increase the amount of contribution: initial contribution (C) is multiplied by leverage (L1). Accordingly, the amount of contribution is lowered when indicator value is extremely high - above Upper contribution threshold (UCT).

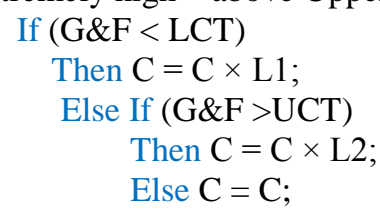

This sum of money is used to purchase the units of fund (PU) for the current units' price (UP):

$$
P U=C / U P
$$

Newly purchased units (PU) are added to the accumulated units (AU). The total amount of accumulated units (AU) increases after each buy operation, but decreases if units are sold (US):

$$
A U_{t}=A U_{t-1}+P U_{t}-U S_{t}
$$

The portfolio value (PV) depends on the fund's unit value. It can be determined at any time. This is done by multiplying the amount of units (AU) by the current unit price (UP). It allows simulating the changes of investment returns and analysing the changes of portfolio value during all investment period:

$$
P V=A U \times U P
$$


In accordance to sentiment indicator the portfolio assets are sold and the profit is taken when strong greed level is observed - exceeds the Sell threshold (ST) value. This is done to prevent sharp drops of portfolio value. At these moments we get Investment income (InI) that is accumulated during the all investment period.

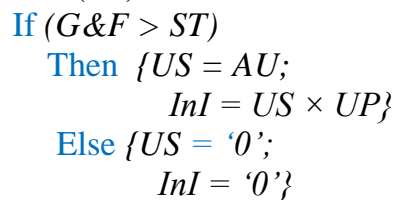

Finally, the return of all investment process (Pr) is determined. It is calculated by deducting all contributions (TC) from the total accumulated amount of money (TI):

$$
\mathrm{Pr}=\mathrm{TI}-\mathrm{TC}
$$

The detailed description of various investment strategies and their performance is presented in the following section.

\section{Research results}

\subsection{Case study of investing to SPDR S\&P 500 ETF}

In this section the results of simulation process of investment to the SPDR S\&P 500 ETF (SPY) is presented. This ETF seeks to provide investment results that, before expenses, correspond generally to the price and yield performance of the S\&P $500 \AA$ Index (WEB, e). The period is from December 2013 to January 2016. Fig. 2 shows, that from the start of this period SPY value was continuously growing. But at the end of the period there were two price drops and the price almost returned to its initial value. This is typical situation then inexperienced investors suffer losses. Further in this section we analyse, how sentiment indicator can prevent from losses during the corrections of stock prices.

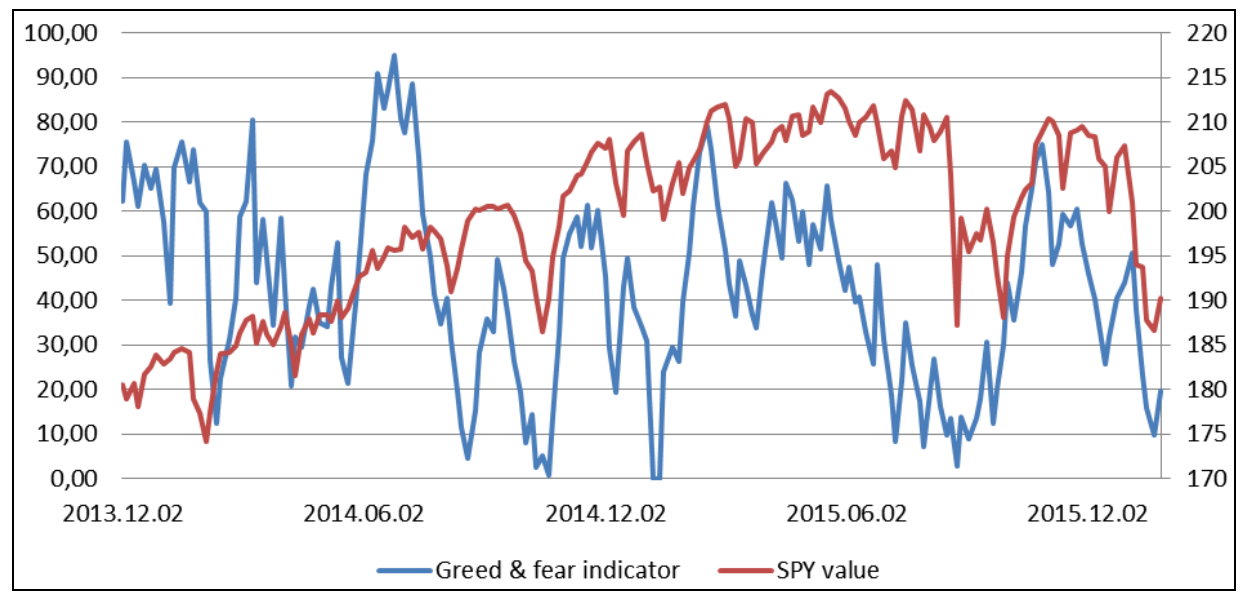

Fig. 2. SPDR S\&P 500 ETF value versus Sentiment indicator

We investigate the case when periodical investments are made by unprofessional investors. It's common for such investment instruments as life insurance funds, pension 
funds or exchange traded funds (ETF). The frequency of contributions is 9 days. The standard amount of contribution is $100 \$$. The decisions to buy or sell fund units are made accordingly to indicator of investors' sentiment.

We investigate six different strategies, but all of them have the same principles:

- When sentiment indicator is less than lower threshold (LCT), we increase the amount of contribution by multiplying it by leverage L1. Usually there are a lot of fears in the market when prices are at the bottom, so we try to use it as opportunity to buy cheaper assets.

- If greed and fear indicator is higher than upper threshold (UCT), we minimize the amount of contribution by multiplying it by leverage L2. Possible values of L2 range from 0 to 1 . This is done to prevent of buying overpriced assets.

- If sentiment is higher than sell threshold (ST), we sell all accumulated units and take profit. This is done to prevent losses as the fall of stock prices is expected.

These principles are completely opposite to the common behaviour of unprofessional investors that lead to losses. The particular coefficients of different strategies are presented in table 1.

Table 1. Coefficients of strategies

\begin{tabular}{lccccc}
\hline & ST & L1 & LCT & L2 & UCT \\
\hline Strategy No. 1 & 60 & 50 & 5 & 0 & 55 \\
Strategy No. 2 & 50 & 10 & 10 & 0,5 & 60 \\
Strategy No. 3 & 65 & 20 & 10 & 0,2 & 65 \\
Strategy No. 4 & 70 & 30 & 10 & 1 & 70 \\
Strategy No. 5 & 55 & 40 & 5 & 0,1 & 60 \\
Strategy No. 6 & 65 & 20 & 20 & 0,2 & 50 \\
\hline
\end{tabular}

The results of these strategies are presented in following figures.

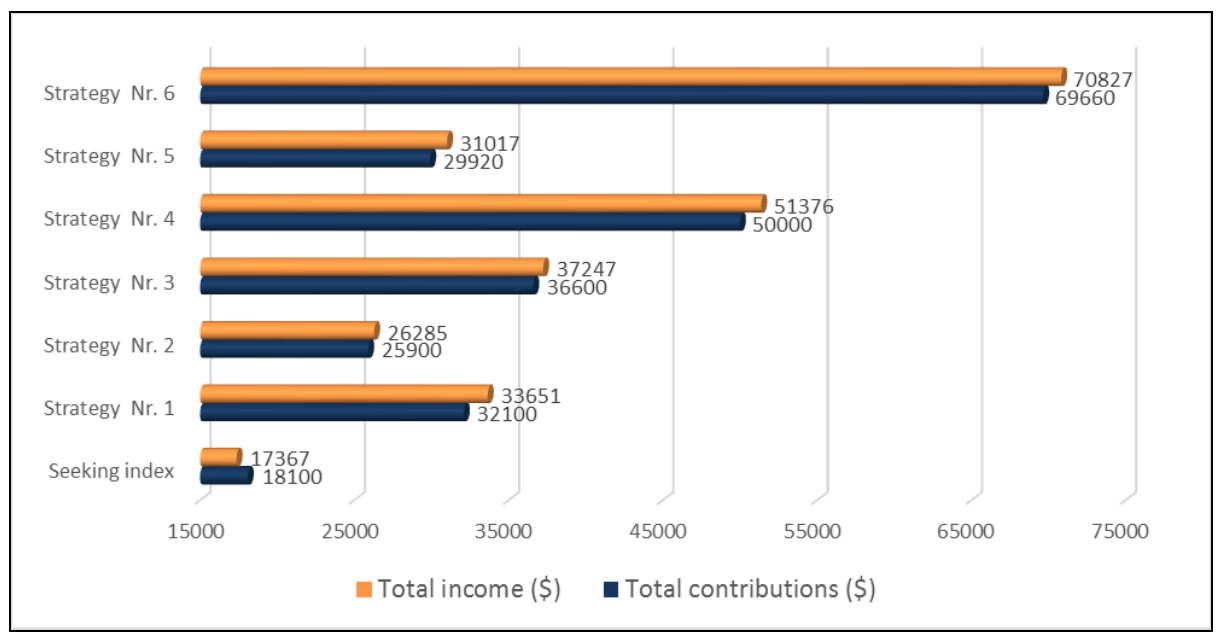

Fig. 3. Contributions vs. investment income 
Fig. 3 presents the total amounts of income and contributions. We can see that investing without using indicator and just following the index lead to losses. In contrast, all 6 strategies were profitable. Strategies no. 4 and no. 6 distinguish by large amounts of money, because they were more aggressive.

To get deeper insight of every strategy, Fig. 4 presents the profit/loss in net value and as percentage of contributions made. It shows that the best strategy (no. 1) lead to profit of $4.83 \%$, while not using indicator lead to loss of $4.05 \%$. This means that the effect of using sentiment indicator was almost $9 \%$. When comparing several strategies, the profit ratio is more important than profit in net value. For example, strategy no. 4 gained more profit in net value, but strategy no. 5 had better profit rate $(3.67 \%$ versus $2.75 \%)$.

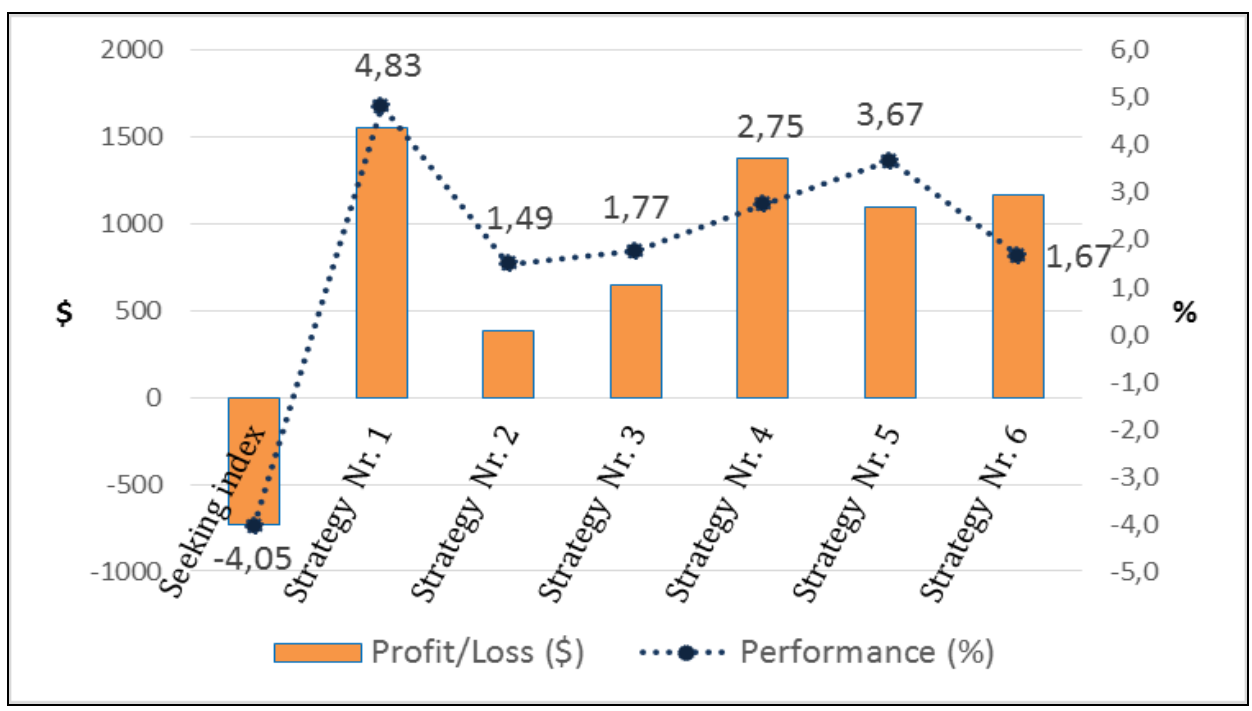

Fig. 4. Comparison of profits

Fig. 5 compares the performance of strategy no. 1 versus benchmark performance (SPDR S\&P 500) and performance of periodical investment to ETF without using indicator.

It looks that benchmark performance is much better. But this is the critical point that should be understood when investigating periodical investing. The performance of benchmark is calculated in accordance to the initial value of the asset price (at the beginning of investment period). When periodic contributions are made, assets may be bought for higher price than that initial price. Then drops of price lead to bigger losses. This is why the graph of performance of investment without using indicator look similar to benchmark graph, but the results are worse. 


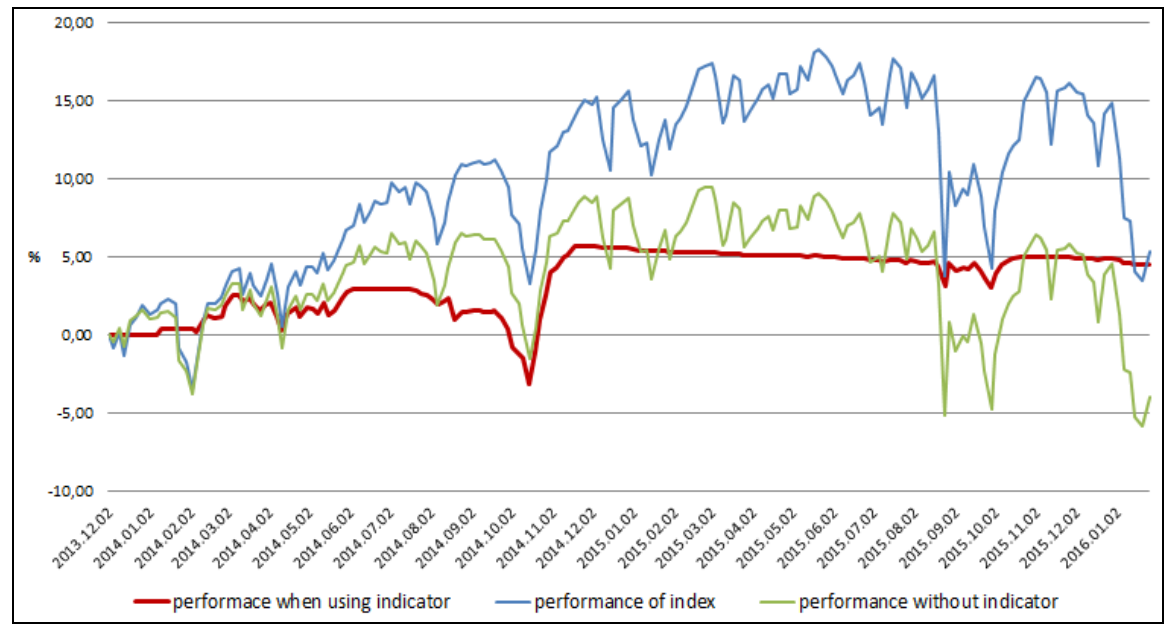

Fig. 5. Performance comparison

Sentiment indicator partially solves this problem. It successfully forecasts price changes, fixes profits and prevent portfolio from big loss of value.

Fig. 6 shows how changes the portfolio value versus total contributions made when using sentiment indicator and investing without it.

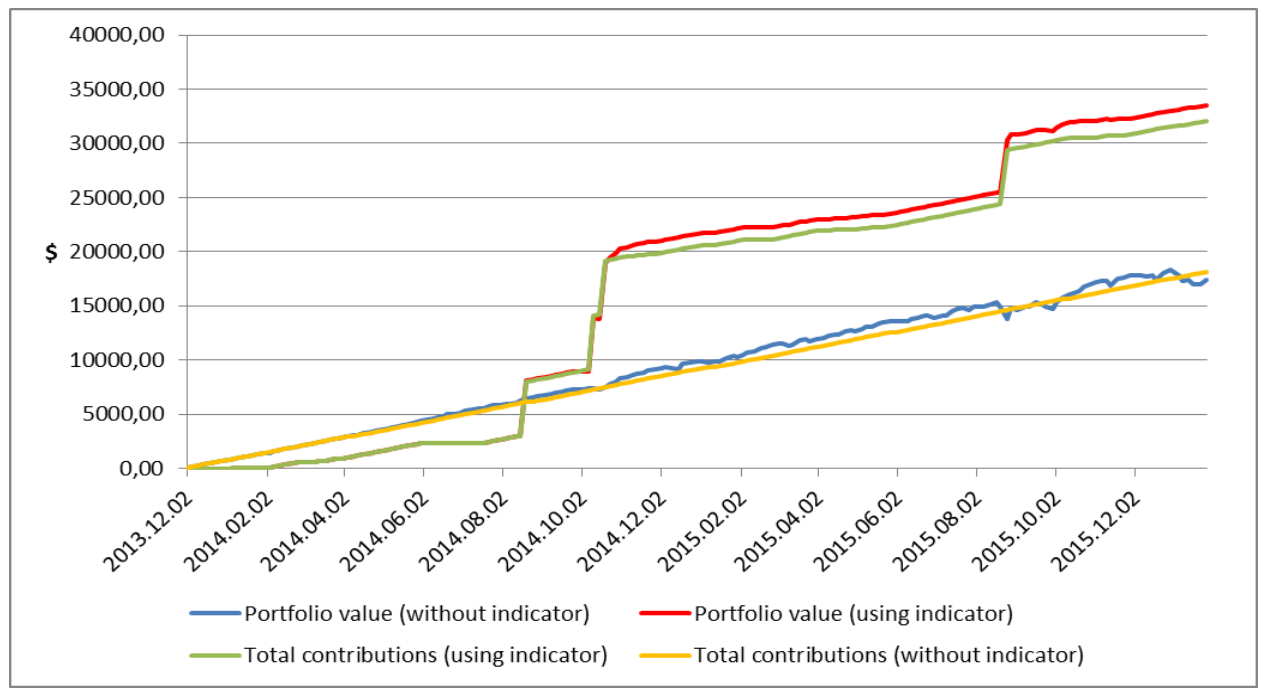

Fig. 6. The changes of portfolio value

We can see that in the case of using investors' sentiment indicator the portfolio value (current portfolio value plus profit already taken off) do not fall below the level of total contributions made. This confirms our initial hypothesis that such indicator can help to predict falls of stock market and prevent losses. 


\subsection{Case study of investing to SPDR Euro STOXX 50}

In the second case we investigated the performance of the same strategies when investing to Europe region stocks - SPDR Euro STOXX 50 ETF (WEB, f).

The condition and period was the same - from December 2013 to January 2016. But as can be seen in Fig. 7, the dynamics of ETF price were absolutely different. At the beginning it was rising, however from June 2016 it began to fall sharply and the final result of the period was $-21 \%$. Our goal was to check, if sentiment indicator can prevent from such big losses.

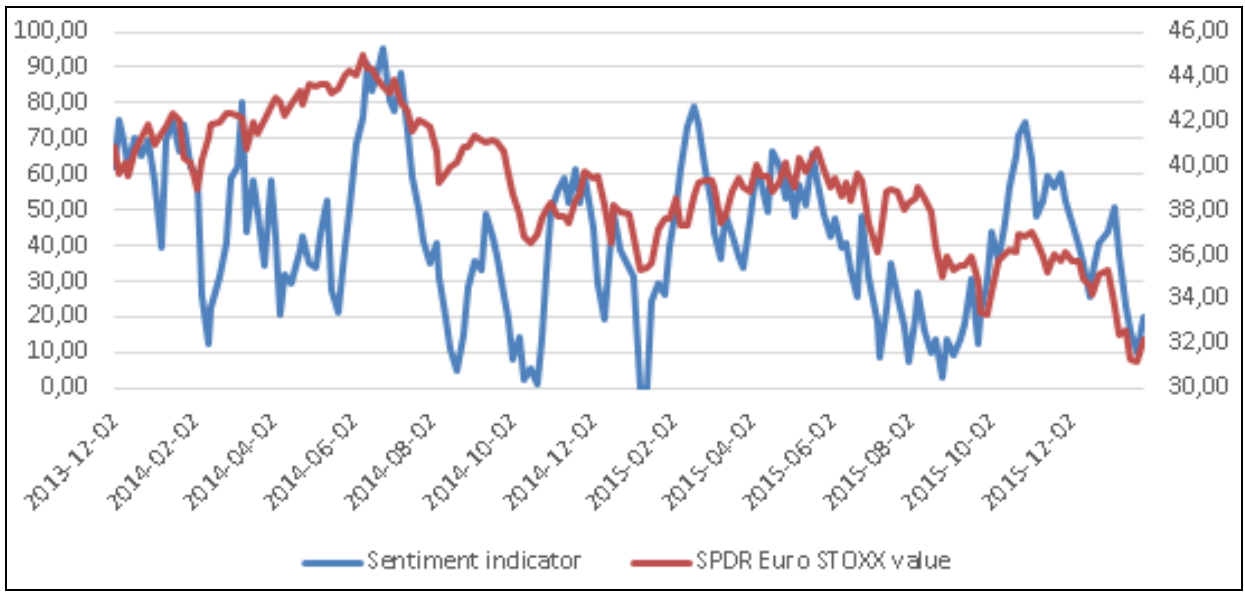

Fig. 7. SPDR S\&P 500 ETF value versus Sentiment indicator

Fig. 8 presents the comparison of results that were got by using strategies determined in table 1.

Firstly, we can see that making periodical contributions (even not using the sentiment indicator), reduced the losses to $7.27 \%$. All strategies based on sentiment indicator had even better profit rates. The first strategy was the best again. Its profit rate was positive $0.53 \%$. This strategy absolutely protected the portfolio from losses. We have to mention, that in this case the strategy no. 6 wasn't successful. Although profit ratio was relatively good $(-3.63 \%)$, but this strategy was very aggressive, much bigger contributions were made, so the loss in net value was the biggest. 


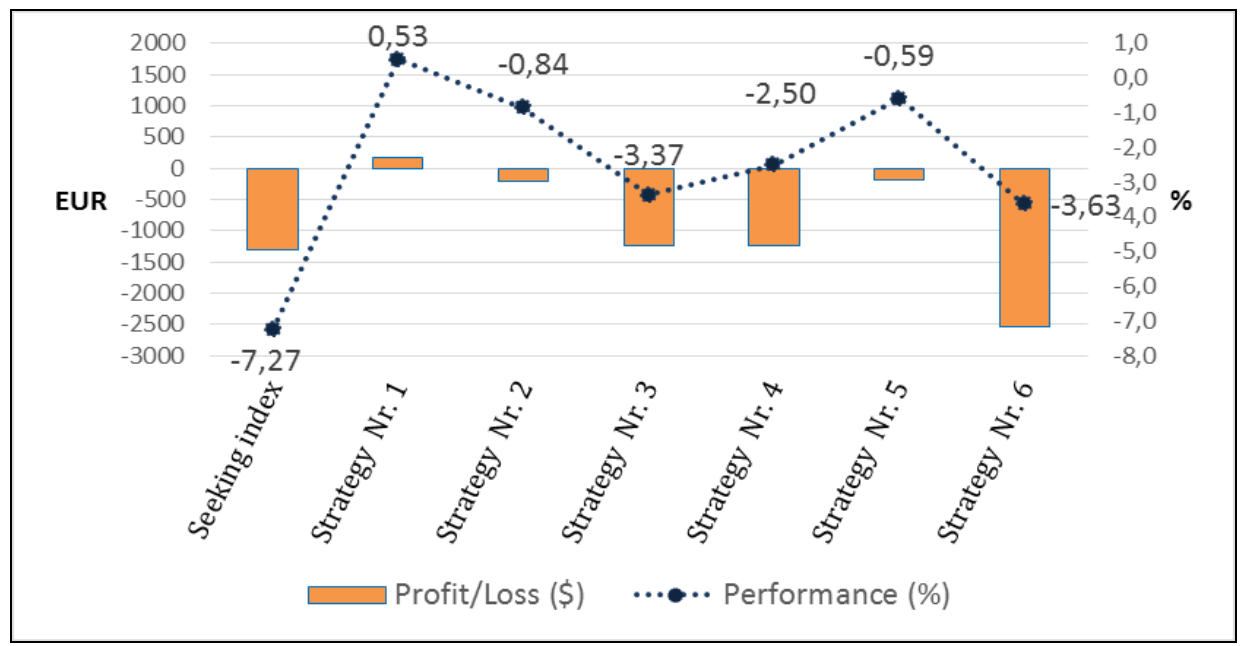

Fig. 8. Comparison of different strategies

Fig. 9 compares the performance of the best strategy versus SPDR EURO STOXX index. It reveals how selling the assets at the right moment and fixing the profit maintains the portfolio profitable.

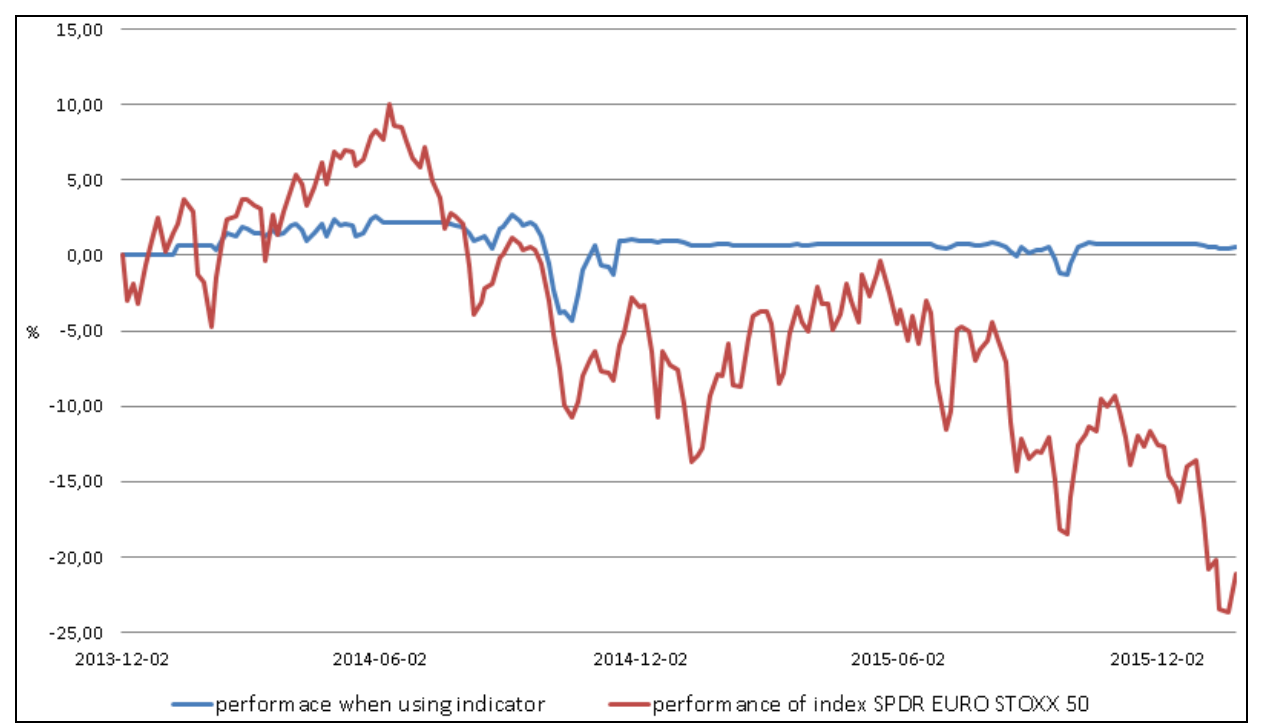

Fig. 9. Performance comparison

All strategies that use sentiment indicator have the same common characteristic - the total amount of contributions are much higher (Fig. 10). This is because the periodical contributions are highly increased when sentiment indicator indicate that asset prices are undervalued. 


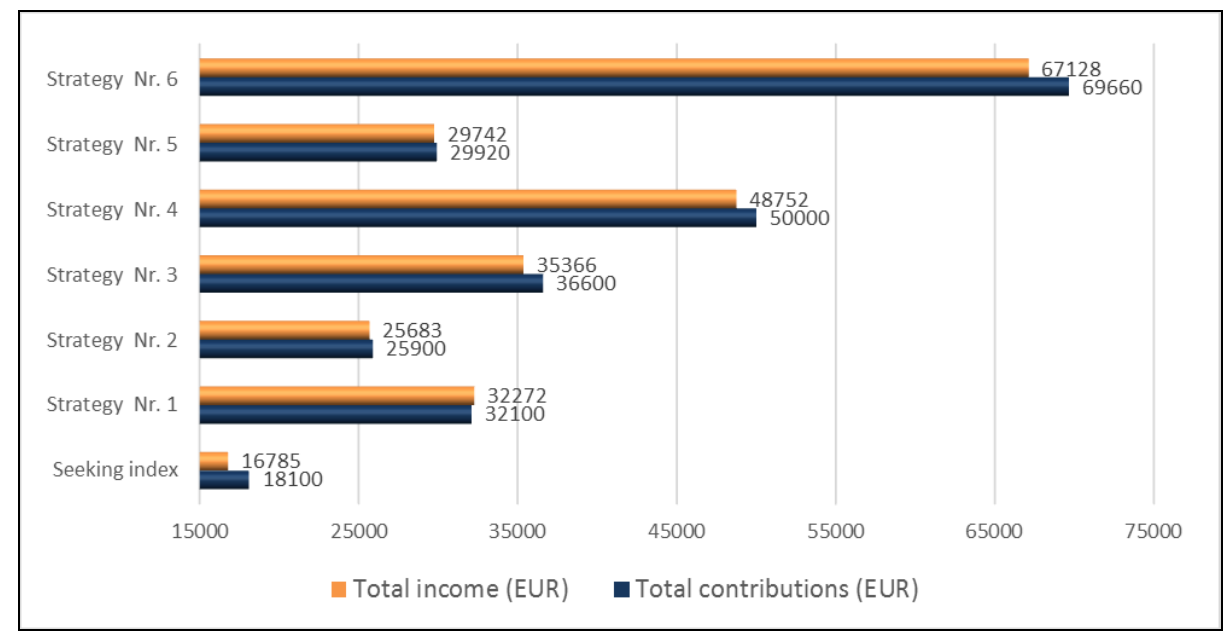

Fig. 10. Contributions vs. investment income

\subsection{Case study of investing to SPDR GOLD SHARES}

In the last case we focused on gold market forecasting which is closely related to market sentiments. For many years gold was used as hedging instrument and the demand for it increases during the financial crisis. Now it becomes more speculative asset, but it is highly correlated with investors' mood. This research shows how investors' sentiment indicator can help to predict the prices of this asset. The process of periodical investment to SPDR Gold Shares ETF was simulated (WEB, g). During the period from December 2013 to January 2016 the price of SPDR Gold Shares ETF was continuously decreasing, so this is also a good way to test if indicator can prevent from losses. The standard amount of contribution was the same $100 \$$. We used the same parameters of six strategies presented in table 1. Fig. 11 presents the values of SPDR Gold ETF price and Sentiment indicator.

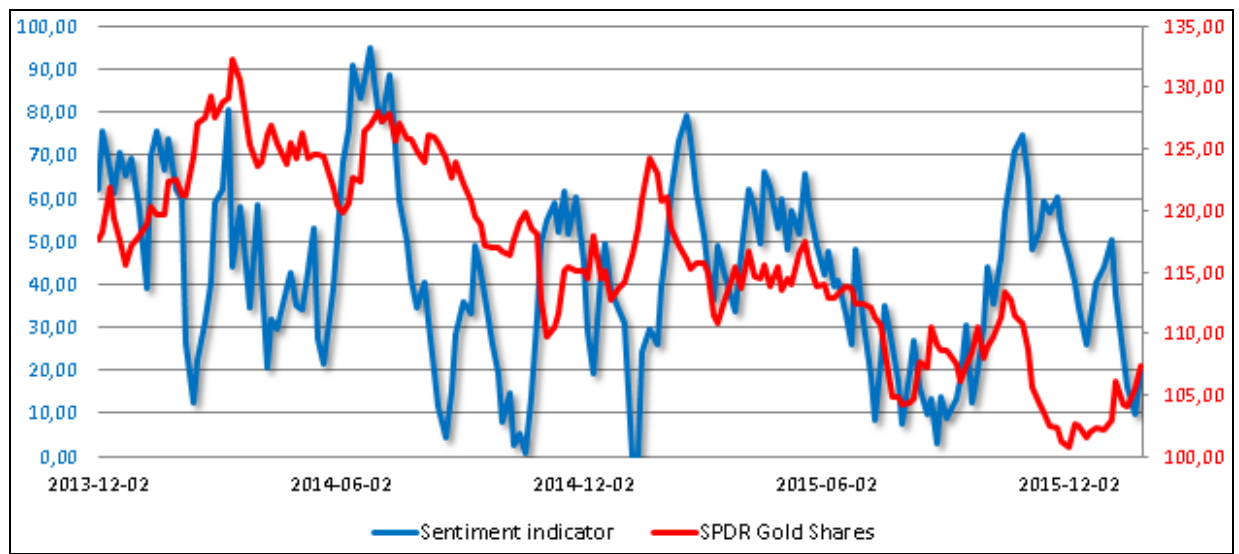

Fig. 11. SPDR Gold shares value versus Sentiment indicator 
The Fig. 12 presents the results of these strategies compared to benchmark (SPDR Gold Shares index) - the profit/loss in net value and as percentage of contributions made. We can see that investing without using sentiment indicator led to losses of $7.27 \%$. However, sentiment indicator enabled to gain much better results. Strategies no. 1, 2 and 5 also led to losses, but they were smaller. The more important fact is that strategies no. 3,4 and 6 made profits during this period of declining gold prices.

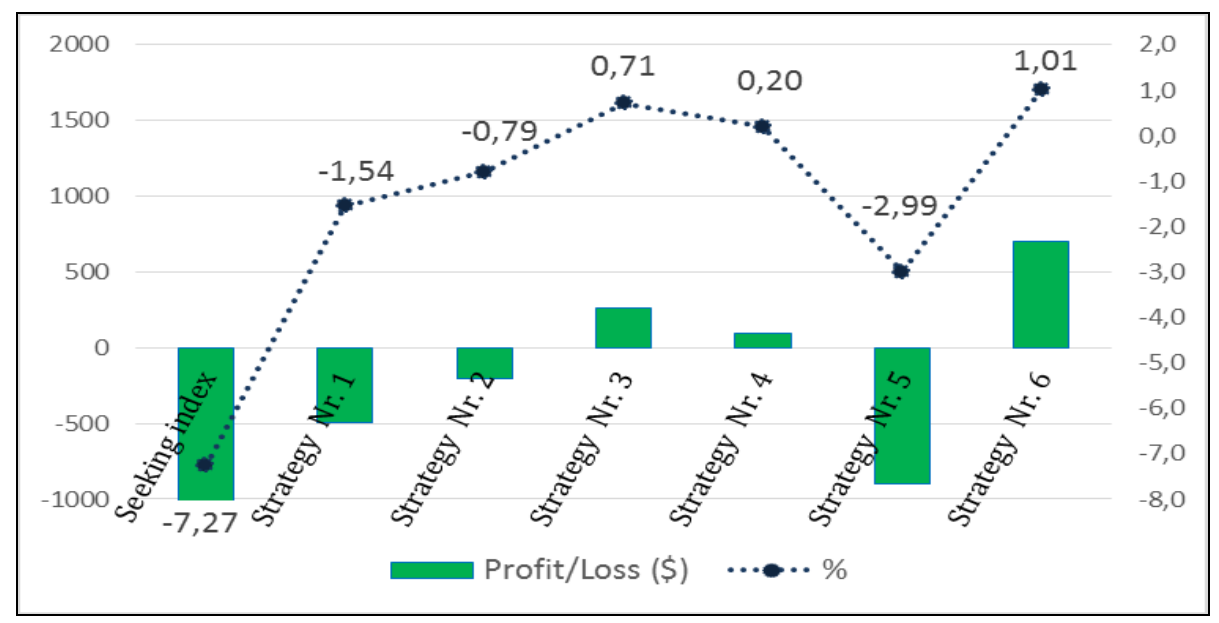

Fig. 12. Comparison of different strategies

In this case the most successful strategy was no. 6 , which gained $1.01 \%$ profit. Fig. 13 shows the changes of portfolio value when using the strategy no. 6 in comparison to benchmark - SPDR Gold Shares index.

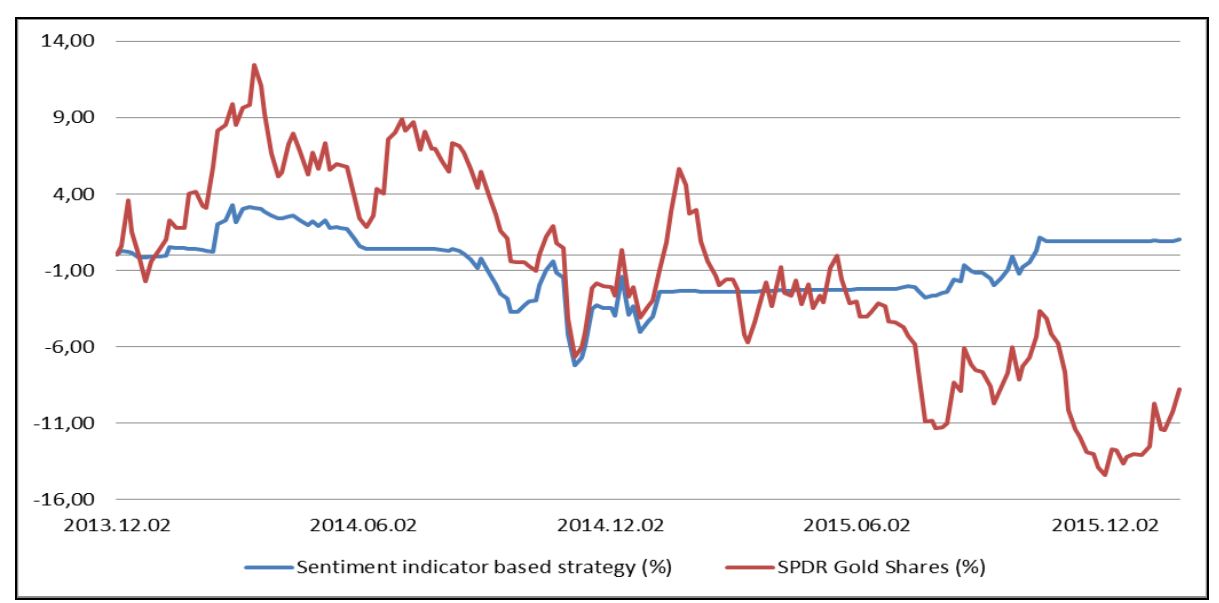

Fig. 13. Performance comparison

We can see that gold price maintained the trend to decrease during all analysed period of time and its volatility was much higher. Fear and greed indicator successfully forecasted the correction of price and prevented from losses. The increase of contributions when the highest fear level was observed let to buy undervalued assets and gain profits. 


\section{Conclusions}

The research results reveal that emotions based investment decisions lead to losses. However, new applications of big data analytics allow extending the scope of indicators that can be used to eliminate this irrational behaviour and increase the investment efficiency. They reveal the hidden patterns of investors' behaviour and enable to better predict financial bubbles and markets crashes. In this research we focused on prediction of anomalous situations in financial markets that usually cause losses. We investigated if investors' sentiment indicator can solve this problem.

Firstly, we presented the literature survey of existing methods for financial crisis. We overviewed both the financial indicators and those determining investors mood. We also presented the general classification of both kinds of these indicators.

The methodology of using investors' sentiment to predict changes of asset prices were suggested. In this research we used indicator based on CNN Fear \& Greed index. We adapted such indicator for long-term periodical investment case. In accordance to investors' sentiment indicator the portfolio assets were sold and the profit was taken when strong greed level was observed. The amount of contribution was also calculated in accordance to sentiment indicator to prevent of buying overpriced assets and try to buy cheaper assets. These principles are completely opposite to the common behaviour of unprofessional investors that lead to losses.

We simulated the investment process to three exchange traded funds: SPDR S\&P 500, SPDR Euro STOXX and SPDR Gold Shares. Six different strategies were investigated. The specific period of time was selected with negative dynamics of asset process. This let to imitate the situations when most investors suffer losses due to irrational behaviour.

The first case of investment to SPDR S\&P 500 showed that the best strategy led to profit of $4.83 \%$, while not using indicator led to loss of $4.05 \%$. This means that the effect of using sentiment indicator was almost $9 \%$.

Secondly, we investigated the case where SPDR Euro STOXX fell by $21 \%$. The goal was to check if sentiment indicator could prevent from such big loss. Even not using the sentiment indicator, but making periodical contributions, reduced the losses to $7.27 \%$. All strategies based on sentiment indicator had better profit rates. The first strategy was the best again and had positive profit rate $-0.53 \%$. This strategy absolutely protected the portfolio from losses.

In the last case the periodical investment to SPDR Gold Shares ETF was simulated. During the selected period of time the price of gold was continuously decreasing, so this was a good case to test if indicator can prevent from losses. Several strategies let to reduce the losses and three of them even gained a profit.

The initial results confirm that indicators of investors mood can successfully forecasted the corrections of asset prices and prevent from losses. Now we need further researches to integrate such indicators to financial crisis prediction models. 


\section{References}

Bollen, J., Mao H., Zeng X.. Twitter Mood Predicts the Stock Market. 2010. Available: http://arxiv.org/abs/1010.3003.

Bordino I, Battiston S, Caldarelli G, Cristelli M, Ukkonen A, Weber I. Web search queries can predict stock market volumes. Plos One. 2012; 7(7):e40014.

Bucevska, V. An analysis of financial crisis by an early warning system model: The case of the EU candidate countries. BEH - Business and Economic Horizons. Volume 4, Issue 1, January 2011, pp. 13-26. ISSN: 1804-1205.

Campbell, J. Y., Empirical Asset Pricing: Eugene Fama, Lars Peter Hansen, and Robert Shiller, 2014. Available: http://ssrn.com/abstract $=2417875$

Chau, F., Deesomsak, R., Koutmos, D. Does investor sentiment really matter? International Review of Financial analysis,Vol. 48, 2016, p. 221-232, Elsevier.

Claessens, S., Kose, M. A. Financial Crises: Explanations, Types, and Implications. IMF Working Paper, 2013.

Fama, E., 1970, "Efficient Capital Markets: A Review of Theory and Empirical Work", Journal of Finance 25, 283-417.

Gruhl, D., Guha R., Kumar R., Novak J., Tomkins A. The Predictive Power of Online Chatter. Proceedings of the Eleventh ACM SIGKDD International Conference on Knowledge Discovery in Data Mining, 78-87. KDD '05. New York, NY, USA.

Guo, K., Sun, Y., Qian, X. Can investor sentiment be used to predict the stock price? Dynamic analysis based on China stock market. Physica A: Statistical Mechanics and its Applications, Vol. 469, 2017, p. 390-396, Elsevier.

Houlihan, P., Creame, G. Can social media and the options market predict the stock market behavior? Stevens Institute of Technology. 2014. Available: https://editorialexpress.com/cgibin/conference/download.cgi?db_name=CEF 2015\&paper_id $=521$

Kristoufek L. Can Google Trends search queries contribute to risk diversification? Scientific reports. 2013; 3. doi: 10.1038/srep02713

Krugman, P. (2001) “Crises: The Next Generation?” Paper prepared for the Razin conference, Tel Aviv University, March.

Krznar, I., 2004. "Currency crisis: Theory and practice with application to Croatia", Working papers W-12, Croatian National Bank.

Liutvinavicius, M., Sakalauskas, V. Dynamic Simulation of Pension Funds' Portfolio. BIS Workshops 2012, volume 127 of Lecture Notes in Business Information Processing, page 69-80. Springer, (2012).

Liutvinavicius, M., Sakalauskas, V. Research of Factors Affecting Pension Funds Efficiency. Social technologies, nr. 1(2), ISSN 2029-7564 (2011).

Mariano, R., Gultekin, B., Ozmucur, S. Models of Economic and Financial Crises. Proceedings of the Middle East Economic Association, 2002. ISSN: 2334-282X

Oliveira, N., Cortez, P., Areal, N. Stock market sentiment lexicon acquisition using microblogging data and statistical measures. Decision Support Systems, Vol. 85, 2016, p. 62-73, 2016, Elsevier.

Ranco, G, Aleksovski, D, Caldarelli, G, Grčar, M, Mozetič, I. The Effects of Twitter Sentiment on Stock Price Returns. PLoS ONE 10(9): e0138441. doi:10.1371/journal.pone.0138441 (2015).

Renault, T. Intraday online investor sentiment and return patterns in the US stock market. Journal of Banking \& Finance, Vol. 84, 2017, p. 25-40, Elsevier.

Schoen, H., Gayo-Avello, D. et al. (2013) "The power of prediction with social media", Internet Research, Vol. 23 Iss: 5, pp.528- 543. 10.1108/IntR-06-2013-0115 
Shahzad, S. J. H., Raza, N., Balcilar, M., Ali, S., Shahbaz, M. Can economic policy uncertainty and investors sentiment predict commodities returns and volatility? Resources Policy, Vol. 53, 2017, p. 208-218, Elsevier.

Shen, G. C., Jia, W.Y. (2014) The Prediction Model of Financial Crisis Based on the Combination of Principle Component Analysis and Support Vector Machine. Open Journal of Social Sciences, 2, 204-212. Available: http://dx.doi.org/10.4236/jss.2014.29035

Shiller, R. J., 2014. "Speculative Asset Prices", American Economic Review, 104(6): 1486-1517. Available: http://cowles.yale.edu/sites/default/files/files/pub/d19/d1936.pdf

Singh, T. R. An ordered probit model of an early warning system for predicting financial crisis in India. Proceedings of the IFC Conference on "Initiatives to address data gaps revealed by the financial crisis", Basel, 2010.

Song, Q., Liu, A., Yang, S. Y. Stock portfolio selection using learning-to-rank algorithms with news sentiment. Neurocomputing, Vol. 264, 2017, p. 20-28, Elsevier.

Tularam, G., Subramanian, B. Modeling of financial crises: a critical analysis of models leading to the global financial crisis. Global journal of business research. Volume 7, nr 3. 2013.

WEB (a). Fear \& Greed Index. [Accessed: 28-Aug-2017]. http://money.cnn.com/data/fear-and-greed/

WEB (b). Social Network for Investors and Traders. [Accessed: 28-Aug-2017]. http://stocktwits.com/

WEB (c). Market Prophit. [Accessed: 28-Aug-2017]. http: //marketprophit. com/

WEB (d). HedgeChatter. The Trusted Provider of Social Media Stock Analysis for the Markets. [Accessed: 28-Aug-2017]. https: / / www. hedgechatter. com/

WEB (e). SPDR S\&P 500 ETF. State Street Global Advisors. [Accessed: 28-Aug-2017]. https://us.spdrs.com/etf/spdr-sp-500-etf-SPY

WEB (f). SPDR Euro STOXX 50 ETF. [Accessed: 28-Aug-2017]. http: / / finance. yahoo. $\mathrm{com} / \mathrm{q}$ ? $\mathrm{s}=\mathrm{FEZ}$

WEB (g). SPDR Gold Shares ETF. [Accessed: 28-Aug-2017]. http: //finance.yahoo. com/q?s=GLD

Received August 27, 2017, accepted September 4, 2017 